\title{
Comparison of the Structures of Ammonium Myristate, Palmitate, and Stearate by X-ray Diffraction, Infrared Spectroscopy, and Infrared Hole Burning
}

\author{
Gu-Sheng Yu, ${ }^{\dagger}$ Hung-Wen Li, Fred Hollander, Robert G. Snyder, and Herbert L. Strauss* \\ Department of Chemistry, University of California, Berkeley, California 94720-1460
}

Received: July 2, 1999; In Final Form: September 21, 1999

\begin{abstract}
X-ray diffraction studies of ammonium myristate and palmitate show crystals that belong to space group $P 2_{1} / n$ with the methylene groups packing in a triclinic subcell. The infrared spectra of the palmitate and stearate are similar as expected, but the bands of the myristate salt show additional splitting in the methylene rocking and twisting bands. A number of other factors of the myristate spectrum and of the infrared hole burning are unique as well. The differences show that the myristate salt has two molecules per spectroscopic unit cell, which are postulated to differ by small rotations of the polar carboxyl groups relative to the plane of the chain. A second form of ammonium myristate is found by crystallizing under different conditions.
\end{abstract}

\section{Introduction}

The arrangement of the hydrocarbon chains in lipids is a major factor in determining their three-dimensional structure. ${ }^{1}$ Usually, at low temperatures, the hydrocarbon molecules are arranged into layers of adjacent all-trans chains. In compounds with a polar end, such as the fatty acid salts we consider here, the typical arrangement consists of bilayers with the hydrocarbons separated by sheets of the polar constituents. There are many variations of this layered arrangement, which can lead to different phases. For example, the different phases can have chains tilted at different angles to the bilayer planes. In addition, the polar components can take up different conformations. The challenge is to determine the various structures, to analyze and understand the delicate interplay of forces that lead to a given phase, and then to relate the structure to the properties of the phase.

Almost all fatty acid compounds have more than one solid phase at a given temperature and pressure. The phases can be related to one another as polymorphs-different arrangements of the chains in the crystal. ${ }^{1}$ For example, stearic acid has several polymorphs, ${ }^{2-10}$ with the number of distinct forms and identification not yet certain. ${ }^{11}$ A subset of such polymorphs are "polytypes", which differ from one another only by different stacking arrangements of otherwise identical layers. For example, the B-form stearic acid has two polytypes. ${ }^{10,12}$ Each series of homologous compounds has a unique set of phases, and the stearic acid examples are just illustrations of the possibilities.

The physical properties of fatty acid soaps are tremendously varied. ${ }^{1,13}$ Most previous studies focused on the metal soaps because of their technological and biological importance. These also exhibit complicated polymorphs, and for example, the evennumbered potassium soaps exist at least in three different forms, ${ }^{1}$ and it has been shown that the structure changes with the cation. In this investigation, we examine mainly the conformation of the chains in the fatty acid ammonium salts and their intralayer interaction. We use a number of tools to elucidate the lowtemperature phases of the salts. These tools include differential scanning calorimetry, X-ray diffraction, and infrared spectroscopy. We assign the infrared spectra following the methods of

† Present address: Industrial Technology Research Institute-Center for Measurement Standards, 321 Kuang Fu Rd., Section 2, Hsinchu, Taiwan 30042, ROC. our study of alkanes. ${ }^{14}$ We also use our new technique of infrared hole burning spectroscopy, ${ }^{15}$ which is sensitive to various relaxation processes and detects subtle conformational changes. We have previously reported the unit cell parameters of ammonium stearate and the spectra produced by hole burning in that compound ${ }^{16}$ In the present work, we present structural and spectral data on the ammonium myristate and palmitate and compare the results for the three compounds.

\section{Experimental Section}

X-ray Diffraction. The crystals of ammonium myristate, palmitate, and stearate were prepared by the vapor diffusion method. ${ }^{17,18}$ The fatty acids, dissolved in an alcoholic solution with concentrated ammonium hydroxide, were placed in small vials. To obtain appropriately sized crystals for X-ray measurements of the myristate and the stearate, small open-ended capillaries with a diameter of $0.2-0.5 \mathrm{~mm}$ were partially submerged in the solution, with one end protruding through the top cover of the vial. This sample vial was then put in a sealed jar together with two other open vials, one filled with acetonitrile, which slowly diffuses to the sample vial and precipitates the crystals, and the other with concentrated ammonium hydroxide, which maintains the ammonium concentration. Crystals form in the solution and in the capillaries, and those in the capillaries can be mounted for the X-ray studies without manipulation. Methanol, a 50-50\% ethanol/butanol mixture, and ethanol were used as solvents for the myristate, palmitate, and stearate, respectively. We also examined a sample of the myristate crystallized from butanol. The palmitate samples crystallized from solution by the same method proved to be suitable for X-ray studies without the use of capillaries.

The crystals of the salts become softer and more fragile with increasing chain length. Even though ammonium stearate crystals of the appropriate size could be obtained using the vapor diffusion method with ethanol as the solvent, the X-ray reflections were not indexable because of imperfections in the crystal. Other solvents (chloroform, methylene chloride, hexanes, petroleum ether, toluene, acetonitrile, $n$-pentane, ethyl ether, and 1-butanol) were tried at different temperatures, but the crystals obtained also proved unsatisfactory. Even after considerable effort, we were able to determine only the unit cell parameters for the stearate. 
TABLE 1: Summary of Crystal Structure of Ammonium Salts

\begin{tabular}{|c|c|}
\hline ammonium myristate & ammonium palmitate \\
\hline \multicolumn{2}{|c|}{ Crystal Data } \\
\hline $\mathrm{C}_{14} \mathrm{NO}_{2} \mathrm{H}_{31}$ & $\mathrm{C}_{16} \mathrm{NO}_{2} \mathrm{H}_{35}$ \\
\hline$M_{\mathrm{r}}=245.40$ & $M_{\mathrm{r}}=273.46$ \\
\hline monoclinic & monoclinic \\
\hline$P 2_{1} / n$ (no. 14) & $P 2_{1} / n($ no. 14$)$ \\
\hline$Z=4$ & $Z=4$ \\
\hline$D_{\text {calc }}=1.030 \mathrm{~g} / \mathrm{cm}^{3}$ & $D_{\text {calc }}=1.033 \mathrm{~g} / \mathrm{cm}^{3}$ \\
\hline \multicolumn{2}{|c|}{ Data Collection } \\
\hline \multicolumn{2}{|c|}{ Mo $\mathrm{K} \alpha$ radiation } \\
\hline \multicolumn{2}{|c|}{$\lambda=0.71069 \AA$} \\
\hline \multicolumn{2}{|c|}{ SMART diffractometer } \\
\hline \multicolumn{2}{|c|}{ Lorentz-polarization correction } \\
\hline$T=180 \mathrm{~K}$ & $T=145 \mathrm{~K}$ \\
\hline 6655 measured reflections & 5444 measured reflections \\
\hline 2330 unique reflections & 2516 unique reflections \\
\hline \multicolumn{2}{|c|}{ Refinement } \\
\hline refined on $F^{2}$ & refined on $F^{2}$ \\
\hline 828 reflections & 894 reflections \\
\hline 161 parameters & 172 parameters \\
\hline$R(F)=0.079$ & $R(F)=0.073$ \\
\hline$\omega R(F)=0.068$ & $\omega R(F)=0.077$ \\
\hline$R_{\mathrm{all}}=0.208$ & $R_{\mathrm{all}}=0.198$ \\
\hline$S=1.77$ & $S=2.04$ \\
\hline$\Delta \rho_{\max }=0.28 \mathrm{e} \AA^{-3}$ & $\Delta \rho_{\max }=0.28 \mathrm{e} \AA^{-3}$ \\
\hline$\Delta \rho_{\min }=-0.33 \mathrm{e}^{-3}$ & $\Delta \rho_{\min }=-0.26 \mathrm{e}^{-3}$ \\
\hline
\end{tabular}

A crystal of ammonium myristate of approximate size 0.04 $\mathrm{mm} \times 0.09 \mathrm{~mm} \times 0.29 \mathrm{~mm}$ in a capillary was used for the X-ray measurements at a temperature of about $180 \mathrm{~K}$; for ammonium palmitate, a bladelike crystal of dimension $0.02 \mathrm{~mm}$ $\times 0.09 \mathrm{~mm} \times 0.46 \mathrm{~mm}$ was mounted on a glass fiber using paratone hydrocarbon oil and examined at $145 \mathrm{~K}$. All measurements were made on a Siemens SMART diffractometer equipped with a CCD detector.

Hole Burning and Infrared Absorption Studies. The samples used for infrared absorption measurements were prepared in small vials in the same way as for the X-ray diffraction studies. A polycrystalline sample was spread between two $\mathrm{KBr}$ plates that were then mounted in a cryostat. That the solvent was completely removed and all the acid completely converted to the salt were confirmed from the infrared spectrum at room temperature. The sample temperature was lowered to $7 \mathrm{~K}$ over the course of a few hours, and the sample was then left many hours to equilibrate before taking further spectra. The infrared spectra of our salts were measured with a Nicolet 850 FTIR spectrometer at $1 \mathrm{~cm}^{-1}$ resolution. For the hole burning studies, a small amount of $\mathrm{D}_{2} \mathrm{O}$ was added to the ammonium hydroxide to produce a low concentration of $\mathrm{NH}_{3} \mathrm{D}^{+}$ions. The hole burning setup has been previously reported. ${ }^{19} \mathrm{An}$ InSb detector was used for both the hole burning and absorption studies in the N-D stretching region, and each spectrum was taken with 64 scans. To cover the mid-infrared range, a MCT/B detector was used with 1024 scans per spectrum.

\section{Structure}

X-ray Diffraction. The X-ray structures of the myristate and the palmitate salts were determined and are summarized in Table 1. The complete structure reports are included in the Supporting Information to this paper. Both salts crystallize in the space group $P 2{ }_{1} / n$ (no. 14). The unit cell dimensions of these salts and of the stearate are summarized in Table 2. The lateral parameters $a, c$, and $\beta$ of the three salts are almost identical. ${ }^{16}$ The $b$ axes of the salts change in accordance with the chain lengths. The unit cells of the myristate and the palmitate are
TABLE 2: Unit Cell Dimensions of Ammonium Fatty Acid Salts

\begin{tabular}{llll}
\hline & $\begin{array}{c}\text { ammonium } \\
\text { myristate }^{a}\end{array}$ & $\begin{array}{c}\text { ammonium } \\
\text { palmitate }^{a}\end{array}$ & $\begin{array}{c}\text { ammonium }^{\text {stearate }} \\
\text { star }^{b}\end{array}$ \\
\hline$a(\AA)$ & $4.1845(3)$ & $4.1669(2)$ & 4.174 \\
$b(\AA)$ & $60.810(4)$ & $67.629(3)$ & 73.93 \\
$c(\AA)$ & $6.3555(4)$ & $6.3772(3)$ & 6.363 \\
$\beta(\mathrm{deg})$ & $101.920(3)$ & $102.022(2)$ & 101.943
\end{tabular}

${ }^{a}$ Monoclinic unit cell. $T=180 \mathrm{~K}$ for myristate, $T=145 \mathrm{~K}$ for palmitate, and $T \approx 180 \mathrm{~K}$ for stearate. ${ }^{b}$ Triclinic unit cell, $\alpha=86.083^{\circ}$, $\gamma=92.380^{\circ}{ }^{16}$

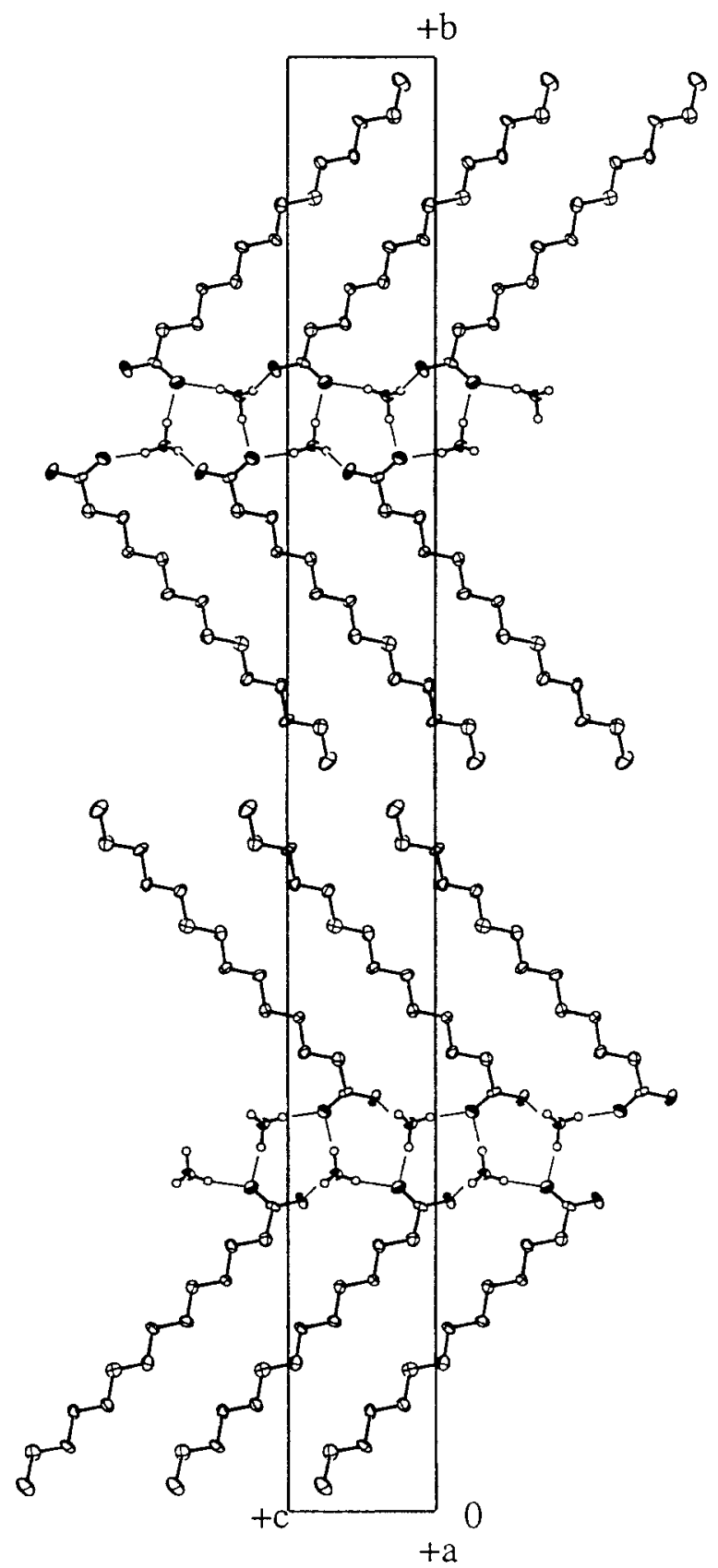

Figure 1. Projection of the structure of ammonium myristate along the $b$ and $c$ axes. Note that the carboxyl groups form a double layer with the ammonium ions between.

monoclinic, while that of the stearate is triclinic. However, the $\alpha$ and $\gamma$ angles of the stearate are close to the $90^{\circ}$ of a monoclinic crystal.

Comparing the two monoclinic compounds, we find that the $\mathrm{CH}_{3}$ ends of the molecules are in the same positions relative to 
TABLE 3: Subcell Dimensions of Triclinic Packing $\mathbf{T}_{\|}{ }^{a}$

\begin{tabular}{lccc}
\hline & $\begin{array}{c}\text { ammonium } \\
\text { myristate }^{b}\end{array}$ & $\begin{array}{c}\text { ammonium } \\
\text { palmitate }^{b}\end{array}$ & trilaurin $^{c}$ \\
\hline$a_{\mathrm{s}}(\AA)$ & 4.40 & 4.38 & 4.287 \\
$b_{\mathrm{s}}(\AA)$ & 5.12 & 5.13 & 5.40 \\
$c_{\mathrm{s}}(\AA)$ & 2.70 & 2.71 & 2.45 \\
$\alpha_{\mathrm{s}}(\mathrm{deg})$ & 79.3 & 79.7 & 74.7 \\
$\beta_{\mathrm{s}}(\mathrm{deg})$ & 105.6 & 105.9 & 108.3 \\
$\gamma_{\mathrm{s}}(\mathrm{deg})$ & 120.9 & 120.8 & 117.4 \\
\multicolumn{4}{c}{ Lateral Section } \\
$a_{\mathrm{o}}(\AA)$ & 4.267 & 4.244 & \\
$b_{\mathrm{o}}(\AA)$ & 5.046 & 5.063 & 4.078 \\
$\gamma_{\mathrm{o}}(\mathrm{deg})$ & 119.38 & 119.34 & 114.38 \\
area $\left(\AA^{2}\right)$ & 19.28 & 19.25 & 19.70
\end{tabular}

${ }^{a}$ The methylene subcell is defined by the values of $a_{\mathrm{s}}, b_{\mathrm{s}}$, and $c_{\mathrm{s}}$ and the associated angles. The lattice vector $c_{\mathrm{o}}$ is in the direction of the methylene chain, and $a_{\mathrm{o}}$ and $b_{\mathrm{o}}$ are perpendicular to it. ${ }^{b}$ The ammonium salts were measured at 180 and $145 \mathrm{~K}$ and trilaurin at room temperature. ${ }^{c}$ Trilauroyl glycerol..$^{20}$

the inversion centers near the $a c$ plane at $y=0,0.5$, etc. The relative positions of the $\mathrm{O}$ atoms of the carboxyl end groups and the $\mathrm{N}$ atoms of the $\mathrm{NH}_{4}{ }^{+}$ions appear similar in the two structures. The angle between the chain and the $b$ axis is approximately the same $\left(47.2^{\circ}\right.$ in the palmitate and $46.9^{\circ}$ in the myristate). The molecules of the fatty acid pack in the unit cell with the acid ends in a double layer with the ammonium ions between, as illustrated in Figure 1. Further packing diagrams of the cells and views of the coordination of the ammonium ions are shown in detail in the Supporting Information.

For samples that have repeated units, like the methylene groups discussed here, it is a useful simplification to describe the structure to a first approximation by a much smaller subcell; that is, the unit cell of a crystal consisting only of infinitely long chains. ${ }^{20,21}$ The hydrocarbon chains of various polymorphic forms are usually found arranged in one of a number of subcell packings, which are classified by the subcell symmetry. An additional specification indicates whether the neighboring chains are parallel or perpendicular. ${ }^{1}$ The X-ray structures show that the polymethylene chains pack in the same manner in ammonium myristate and ammonium palmitate with the same triclinic parallel $\left(T_{\| \mid}\right)$methylene subcell. This might have been expected, since this packing is the same as for the B form of potassium fatty acid salts. ${ }^{22}$ The dimensions of the subcell are listed in Table 3. The packing of the chains can also be visualized by considering the lateral packing, that is, the packing in a plane perpendicular to the chain axis. ${ }^{20}$ This axis is designated $c_{\mathrm{o}}$ and the parameters of the lateral plane are then $a_{\mathrm{o}}, b_{\mathrm{o}}$, and $\gamma_{\mathrm{o}}$. They are listed in Table 3 together with the parameters for trilaurin (trilauroyl glycerol), the compound used to illustrate the calculation of lateral packing. ${ }^{20}$ The similar lateral dimensions of the different compounds result from nearly close packing of the hydrocarbon chains. ${ }^{23}$

Each ammonium ion participates in four hydrogen bonds (Figure 2). As seen in Table 4, the hydrogen bond distances (as measured by the heavy atoms) are similar.

Infrared Absorption Spectra. We have examined and compared the mid-infrared spectra of the fatty acid salts, especially in the methylene twisting, wagging, and rocking regions, which are sensitive to both chain conformation and packing interactions. ${ }^{14}$ Infrared absorption spectra of ammonium myristate, palmitate, and stearate at $7 \mathrm{~K}$ from 500 to $1600 \mathrm{~cm}^{-1}$ are shown in Figure 3. The methylene twisting and wagging bands are shown on an expanded scale in Figure 4 (1150-1400 $\left.\mathrm{cm}^{-1}\right)$. The methylene rocking bands are shown in Figure 5 $\left(660-1140 \mathrm{~cm}^{-1}\right)$.
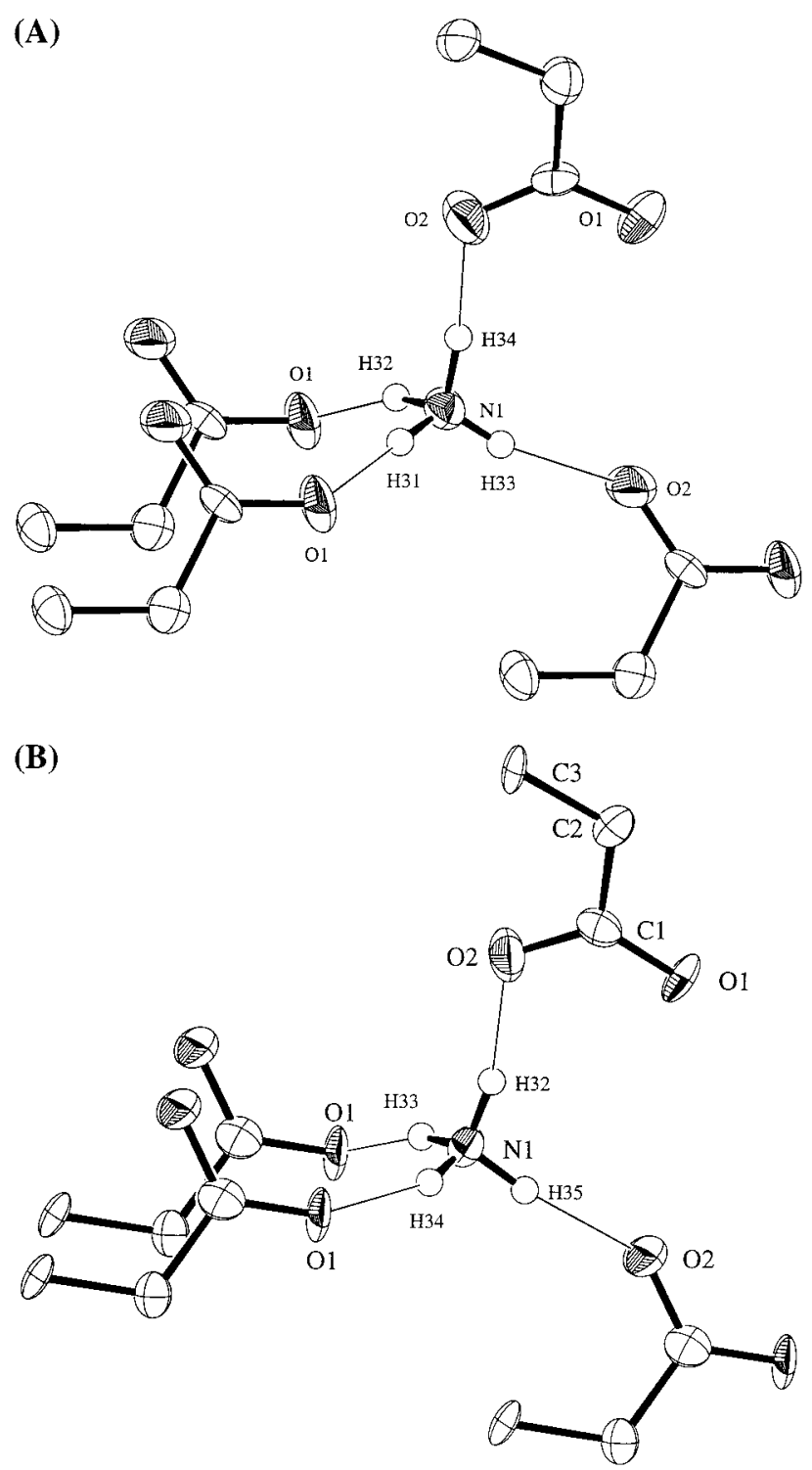

Figure 2. (A) ORTEP plot of the atoms surrounding the ammonium ion in ammonium myristate. Note the large thermal ellipsoids for the $\mathrm{O}$ atoms. (B) ORTEP plot for ammonium palmitate. Note the difference in the thermal ellipsoids, for $\mathrm{O}(2)$, for example, between the myristate and the palmitate.

TABLE 4: Hydrogen Bond Parameters of Ammonium Fatty Acid Salts

\begin{tabular}{lcccc}
\hline $\mathrm{A}-\mathrm{H} \cdots \mathrm{B}$ & $\mathrm{A}-\mathrm{H}(\AA)$ & $\mathrm{H} \cdots \mathrm{B}(\AA)$ & $\mathrm{A} \cdots \mathrm{B}(\AA)$ & $\angle \mathrm{A}-\mathrm{H} \cdots \mathrm{B}(\mathrm{deg})$ \\
\hline \multicolumn{5}{c}{ Ammonium Myristate } \\
$\mathrm{N}-\mathrm{H}_{31} \cdots \mathrm{O}_{1}$ & 0.98 & 1.79 & 2.777 & 179.4 \\
$\mathrm{~N}-\mathrm{H}_{32} \cdots \mathrm{O}_{1}$ & 0.98 & 1.82 & 2.779 & 162.6 \\
$\mathrm{~N}-\mathrm{H}_{33} \cdots \mathrm{O}_{2}$ & 0.87 & 1.95 & 2.763 & 160.0 \\
$\mathrm{~N}-\mathrm{H}_{34} \cdots \mathrm{O}_{2}$ & 0.98 & 1.81 & 2.782 & 165.5 \\
\multicolumn{5}{c}{ Ammonium Palmitate } \\
$\mathrm{N}-\mathrm{H}_{34} \cdots \mathrm{O}_{1}$ & 0.96 & 1.88 & 2.794 & 157.7 \\
$\mathrm{~N}-\mathrm{H}_{33} \cdots \mathrm{O}_{1}$ & 0.95 & 1.86 & 2.768 & 165.6 \\
$\mathrm{~N}-\mathrm{H}_{35} \cdots \mathrm{O}_{2}$ & 0.96 & 1.85 & 2.763 & 171.6 \\
$\mathrm{~N}-\mathrm{H}_{32} \cdots \mathrm{O}_{2}$ & 0.95 & 1.84 & 2.791 & 164.2
\end{tabular}

Although the subcell structures of the myristate and palmitate as determined by X-ray appear to be identical, their IR spectra are significantly different. Many of the methylene twisting and rocking bands have more than one component for the myristate, whereas only one is observed for the palmitate and the stearate. For example, as Figure 5 shows, the rocking bands around 720 and $750 \mathrm{~cm}^{-1}$ split for the myristate but not for the palmitate 


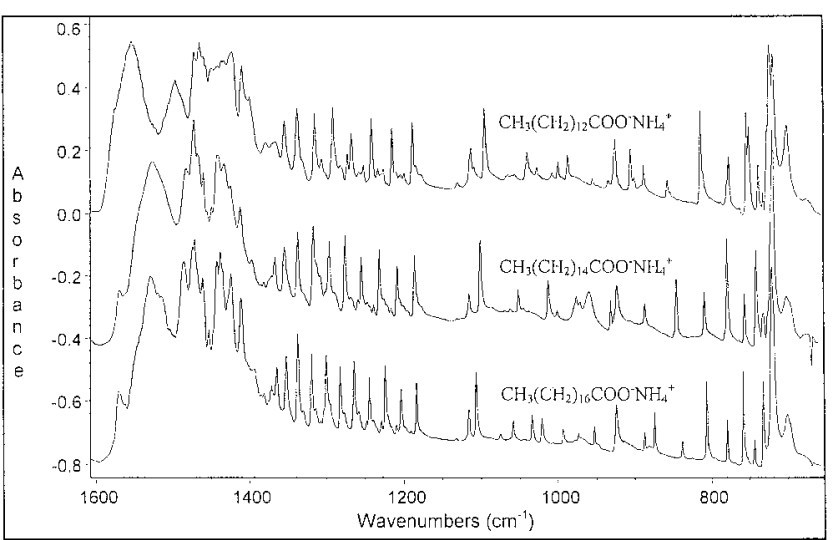

Figure 3. Infrared absorption spectra of ammonium myristate, palmitate, and stearate (top to bottom) from 500 to $1600 \mathrm{~cm}^{-1}$ at $7 \mathrm{~K}$.

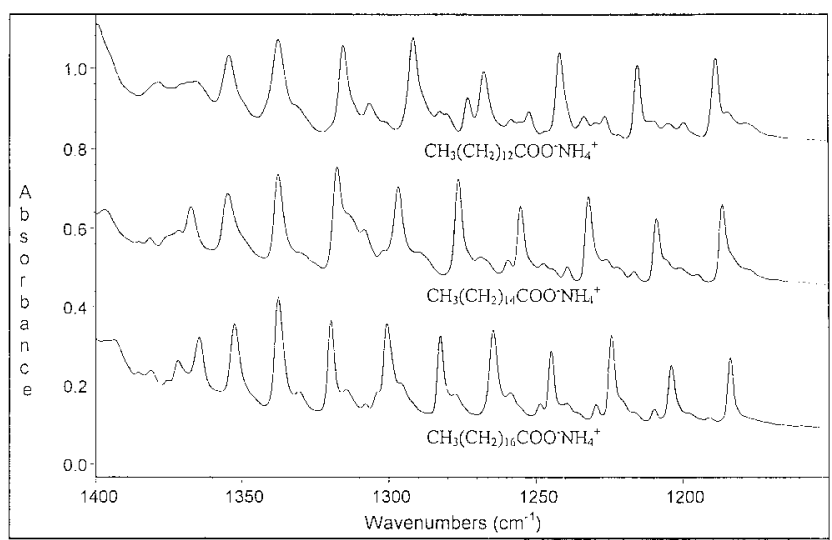

Figure 4. The same as Figure 3 on an expanded scale from 1150 to $1400 \mathrm{~cm}^{-1}$. This region shows the methylene twisting and wagging bands.

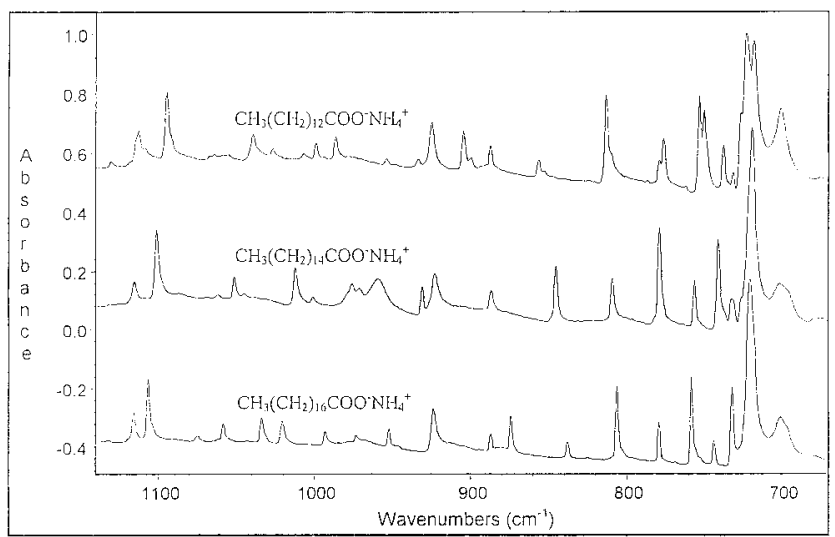

Figure 5. The same as Figure 3 on an expanded scale from 660 to $1140 \mathrm{~cm}^{-1}$. This regions shows the methylene rocking bands.

and stearate. Splitting of the methylene twisting and rocking bands, which results from interchain vibrational coupling, is often observed in the infrared spectra of crystals containing polymethylene chains. The existence of this splitting is usually determined by the symmetry of the methylene subcell. ${ }^{14,24,25}$ Since the myristate and palmitate apparently have the same subcell, we must look elsewhere to explain the difference in the spectra.

The splitting observed for the myristate suggests that the spectroscopic (primitive) unit cell associated with a single layer of the myristate chains contains two chains. A possibility is that each molecule of the pair has the carboxyl groups rotated slightly about the $\mathrm{CH}_{2}-\mathrm{COO}^{-}$bond to reduce the unit cell

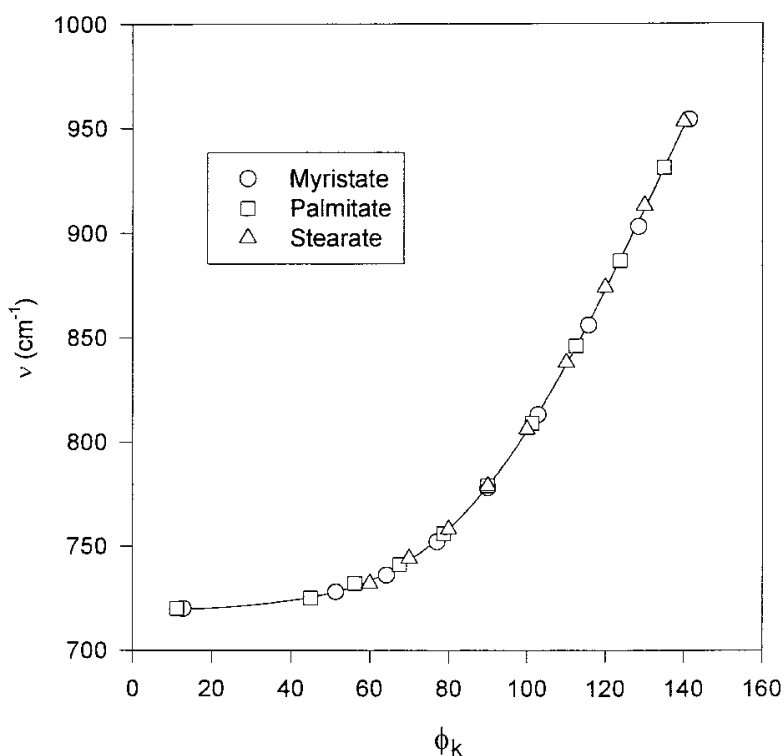

Figure 6. The dispersion curve for the methylene rocking progression bands in the three ammonium salts. The phase angle $\phi_{k}$ is $k \pi /(m+2)$ for the rocking and twisting bands and is $k \pi /(m+1)$ for the wagging bands. ${ }^{26-29}$ The number of the methylene groups, $m$, in the compounds is 12,14 , and 16 for the myristate, palmitate, and stearate, respectively. Since the points for all three compounds fall on the same curve, all three have polymethylene chains with the same all-trans conformation.

symmetry from what it would be with molecules of identical conformation

That the carboxyl group can affect the spectra of these three salts is indicated by the presence of bands representing all the methylene twisting and rocking modes instead of every other one as occurs in the spectra of the $n$-alkanes. The presence of the $\mathrm{COO}^{-}$group reduces the symmetry of an individual chain compared to that of an alkane, allowing more infrared modes. The strength of the bands indicates strong interaction between the $\mathrm{COO}^{-}$group and the rest of the chain.

To reiterate, although the presence of the carboxyl groups accounts for the existence of all the methylene twisting and rocking modes, a further distortion of the chains is necessary to account for the splitting in the myristate. In keeping with the conclusion that the chains differ in the myristate, the intense bands in the $\mathrm{CO}$ stretching regions differ between the myristate and the other salts.

The IR spectra do confirm the diffraction finding that all the $\mathrm{CH}_{2}-\mathrm{CH}_{2}$ bonds of the chains are in the trans conformation. The bands in Figure 4 are members of twisting and wagging progressions, and those in Figure 5 are of rocking progressions. The bands of each progression can be labeled by a phase angle $\phi_{k}$, where $k$ labels the wave vector, and a plot of frequency of each band against the phase angle $\phi_{k}=k \pi /(m+1), k=1,2$, ..., $m$, results in a dispersion curve. For the wagging modes, $m$ is the number of methylene groups in the chain, while for the twisting and rocking modes one is added to $m$ to account for the coupling to the methyl group. ${ }^{26-29}$ Figure 6 shows that the rocking bands of all three fatty acid salts fall into the same dispersion curve, and this is also true for the twisting and wagging bands. Therefore, all the alkanoate chains have the same conformation. The assignments of these progression bands are shown in Tables 5-7.

How can the X-ray structures appear to be the same for the myristate and the palmitate, while the infrared spectra show them to be clearly different? The thermal ellipsoids for the two compounds differ as shown in Table 8. In particular, the thermal ellipsoids are uniformly larger for the myristate. For example, 
TABLE 5: Assignment of Ammonium Alkanonate Rocking Bands at $7 \mathrm{~K}^{a}$

\begin{tabular}{|c|c|c|c|c|c|c|}
\hline \multirow[b]{2}{*}{$k$} & \multicolumn{2}{|c|}{$\mathrm{A}^{-} \mathrm{C}_{14}$} & \multicolumn{2}{|c|}{$\mathrm{A}^{-} \mathrm{C}_{16}$} & \multicolumn{2}{|c|}{$\mathrm{A}^{-} \mathrm{C}_{18}$} \\
\hline & $\begin{array}{c}v_{\mathrm{obs}} \\
\left(\mathrm{cm}^{-1}\right)\end{array}$ & $\begin{array}{c}\phi_{k} \\
(\mathrm{deg})\end{array}$ & $\begin{array}{c}v_{\text {obs }} \\
\left(\mathrm{cm}^{-1}\right)\end{array}$ & $\begin{array}{c}\phi_{k} \\
(\mathrm{deg})\end{array}$ & $\begin{array}{c}v_{\mathrm{obs}} \\
\left(\mathrm{cm}^{-1}\right)\end{array}$ & $\begin{array}{c}\phi_{k} \\
(\mathrm{deg})\end{array}$ \\
\hline 1 & 720 & 12.8 & 720 & 11.2 & & 10.0 \\
\hline 2 & & 25.7 & & 22.5 & & 20.0 \\
\hline 3 & & 38.5 & & 33.7 & & 30.0 \\
\hline 4 & 728 & 51.4 & 725 & 45.0 & & 40.0 \\
\hline 5 & 736 & 64.3 & 732 & 56.2 & & 50.0 \\
\hline 6 & 752 & 77.1 & 741 & 67.5 & 732 & 60.0 \\
\hline 7 & 778 & 90.0 & 756 & 78.7 & 744 & 70.0 \\
\hline 8 & 813 & 102.8 & 779 & 90.0 & 758 & 80.0 \\
\hline 9 & 856 & 115.7 & 809 & 101.2 & 779 & 90.0 \\
\hline 10 & 903 & 128.6 & 846 & 112.5 & 806 & 100.0 \\
\hline 11 & 954 & 141.4 & 887 & 123.7 & 838 & 110.0 \\
\hline 12 & & 154.3 & 931 & 135.0 & 874 & 120.0 \\
\hline 13 & & 167.1 & & 146.2 & 913 & 130.0 \\
\hline 14 & & & & 157.5 & 953 & 140.0 \\
\hline 15 & & & & & & 150.0 \\
\hline 16 & & & & & & 160.0 \\
\hline
\end{tabular}

TABLE 6: Assignment of Ammonium Alkanonate Wagging Bands at $7 \mathrm{~K}^{a}$

\begin{tabular}{|c|c|c|c|c|c|c|}
\hline \multirow[b]{2}{*}{$k$} & \multicolumn{2}{|c|}{$\mathrm{A}^{-} \mathrm{C}_{14}$} & \multicolumn{2}{|c|}{$\mathrm{A}^{-} \mathrm{C}_{16}$} & \multicolumn{2}{|c|}{$\mathrm{A}^{-} \mathrm{C}_{18}$} \\
\hline & $\begin{array}{c}v_{\text {obs }} \\
\left(\mathrm{cm}^{-1}\right)\end{array}$ & $\begin{array}{c}\phi_{k} \\
(\mathrm{deg})\end{array}$ & $\begin{array}{c}v_{\text {obs }} \\
\left(\mathrm{cm}^{-1}\right)\end{array}$ & $\begin{array}{c}\phi_{k} \\
(\mathrm{deg})\end{array}$ & $\begin{array}{c}v_{\text {obs }} \\
\left(\mathrm{cm}^{-1}\right)\end{array}$ & $\begin{array}{c}\phi_{k} \\
(\mathrm{deg})\end{array}$ \\
\hline 1 & 1188 & 13.8 & 1186 & 12.0 & 1184 & 10.6 \\
\hline 2 & 1215 & 27.7 & 1209 & 24.0 & 1204 & 21.2 \\
\hline 3 & 1242 & 41.5 & 1232 & 36.0 & 1225 & 31.8 \\
\hline 4 & 1268 & 55.4 & 1255 & 48.0 & 1245 & 42.4 \\
\hline 5 & 1273 & 55.4 & 1276 & 60.0 & 1265 & 52.9 \\
\hline 6 & 1292 & 69.2 & 1297 & 72.0 & 1283 & 63.2 \\
\hline 7 & 1316 & 83.1 & 1318 & 84.0 & 1301 & 74.1 \\
\hline 8 & 1338 & 96.6 & 1338 & 96.0 & 1320 & 84.7 \\
\hline 9 & 1355 & 110.8 & 1355 & 108.0 & 1338 & 95.3 \\
\hline 10 & & & 1367 & 120.0 & 1353 & 105.9 \\
\hline 11 & & & & & 1365 & 116.5 \\
\hline
\end{tabular}

${ }^{a} \phi_{k}=k \pi /(m+1)$, where $m$ is the number of methylene groups in the compound. ${ }^{26-29}$

TABLE 7: Assignment of Ammonium Alkanonate Twisting Bands at $7 \mathrm{~K}^{a}$

\begin{tabular}{|c|c|c|c|c|c|c|c|c|c|}
\hline \multirow[b]{2}{*}{$k$} & \multicolumn{3}{|c|}{$\mathrm{A}^{-} \mathrm{C}_{14}$} & \multicolumn{3}{|c|}{$\mathrm{A}^{-} \mathrm{C}_{16}$} & \multicolumn{3}{|c|}{$\mathrm{A}^{-} \mathrm{C}_{18}$} \\
\hline & $\begin{array}{c}v_{\mathrm{obs}} \\
\left(\mathrm{cm}^{-1}\right)\end{array}$ & $\begin{array}{c}v_{\mathrm{calc}^{b}} \\
\left(\mathrm{~cm}^{-1}\right)\end{array}$ & $\begin{array}{c}\phi_{k} \\
\text { (deg) }\end{array}$ & $\begin{array}{c}v_{\mathrm{obs}} \\
\left(\mathrm{cm}^{-1}\right)\end{array}$ & $\begin{array}{c}v_{\text {calc }} \\
\left(\mathrm{cm}^{-1}\right)\end{array}$ & $\begin{array}{c}\phi_{k} \\
(\mathrm{deg})\end{array}$ & $\begin{array}{c}v_{\mathrm{obs}} \\
\left(\mathrm{cm}^{-1}\right)\end{array}$ & $\begin{array}{c}v_{\text {calc }} \\
\left(\mathrm{cm}^{-1}\right)\end{array}$ & $\begin{array}{c}\phi_{k} \\
\text { (deg) }\end{array}$ \\
\hline 18 & & & & & & & & 1174 & 180.0 \\
\hline 17 & & & & & & & 1190 & & 16 \\
\hline 16 & & & & 1176 & 1174 & 180.0 & 1210 & 1210 & 160.0 \\
\hline 15 & & & & 119 & 1194 & 168.8 & 1230 & 1228 & 149.9 \\
\hline 14 & 1184 & 1174 & 180.0 & 1217 & 1214 & 157.5 & 1249 & 1246 & 140.0 \\
\hline 13 & 1199 & 1197 & 167.2 & 1239 & 1234 & 146.2 & 1261 & 1264 & 129.9 \\
\hline 12 & 1226 & 1220 & 154.3 & 1259 & 1254 & 135.0 & 1280 & 1282 & 120.0 \\
\hline 11 & 1252 & 1243 & 141.5 & & 1274 & 123.8 & 1299 & 1300 & 109.9 \\
\hline 10 & 1273 & 1266 & 128.5 & & 1295 & 112.5 & & & \\
\hline 9 & 1288 & 1289 & 115.7 & & & & & & \\
\hline
\end{tabular}

${ }^{a} \phi_{k}=k \pi /[(m+1)+1]$, where $m$ is the number of methylene groups in the compound. ${ }^{26-29}{ }^{b}$ The calculated frequency is given by $v_{k}\left(\mathrm{~cm}^{-1}\right)$ $=1497-323\left(\phi_{k} / \pi\right)$.

for the second oxygen $(\mathrm{O} 2)$, the isotropic $\mathrm{B}$ factor is $4.1 \pm 0.2$ for the myristate and $3.0 \pm 0.2$ for the palmitate. The direction of the apparent thermal motion also differs, as can be seen most easily from expanded ORTEP plots of the myristate and palmitate (Figure 2). The thermal ellipsoids are larger for the myristate than the palmitate at all comparable positions, which suggests some disorder (either static or dynamic). A rotation
TABLE 8: Thermal Factors $B_{\text {eq }}\left(\AA^{2}\right)$ of Heavy Atoms in Ammonium Myristate and Palmitate ${ }^{a}$

\begin{tabular}{lcc}
\hline atom & myristate & palmitate \\
\hline O1 & $3.2(2)$ & $3.1(2)$ \\
O2 & $4.1(2)$ & $3.0(2)$ \\
N1 & $2.3(2)$ & $2.0(2)$ \\
C1 & $2.2(2)$ & $2.0(3)$ \\
C2 & $2.9(2)$ & $2.0(3)$ \\
C3 & $2.9(2)$ & $1.7(2)$ \\
C4 & $2.5(2)$ & $1.9(2)$ \\
C5 & $2.1(2)$ & $2.0(2)$ \\
C6 & $2.4(2)$ & $2.0(2)$ \\
C7 & $2.7(2)$ & $1.7(2)$ \\
C8 & $3.0(2)$ & $2.0(2)$ \\
C9 & $2.6(2)$ & $1.9(3)$ \\
C10 & $2.9(2)$ & $1.9(2)$ \\
C11 & $2.4(2)$ & $1.6(2)$ \\
C12 13 & $1.9(2)$ \\
C13 14 & $2.7(2)$ & $2.4(2)$ \\
C15 & $4.0(3)$ & $2.1(3)$ \\
C16 & $4.7(3)$ & $3.7(3)$ \\
& & $3.5(3)$
\end{tabular}

${ }^{a}$ The myristate ( 14 carbons) at $180 \mathrm{~K}$; the palmitate ( 16 carbons) at $145 \mathrm{~K}$.

of the carboxyl group is consistent with the X-ray and infrared evidence, but the displacement of this group is small and maybe hidden in the thermal ellipsoids. ${ }^{30,31}$

We have also found a second form of ammonium myristate in crystals grown from butanol solution. These crystals have very different infrared spectra with a very complicated methylene twisting region. They may contain chains in a conformation with a gauche $\mathrm{CH}_{2}-\mathrm{CH}_{2}$ bond nearest the carboxyl group. The crystals may be similar to the A-super form of the fatty acids (like lauric acid ${ }^{7}$ ) in which there are two sets of chains with different conformations. One set has all the carbon atoms in a plane, but the other has the carboxyl group rotated at the $\mathrm{C} 1-\mathrm{C} 2$ bond. We call this second form of the myristate, "A" and call the form we investigated more thoroughly, "B". In the case of potassium soaps, for soaps containing 4-12 carbon atoms, the A form is preferred, while for soaps containing 1218 carbon atoms, the $\mathrm{B}$ form is the preferred polymorph. ${ }^{1}$ Assuming ammonium soaps follow a similar pattern, the myristate salt, containing 14 carbon atoms, can form either the A or the B polymorph, depending on the details of the crystallization conditions.

Differential Scanning Calorimetry. To find further evidence for this new phase, DSC measurements were carried out on the different samples of the ammonium myristate using a Hart Scientific model 707 calorimeter. The calorimeter was run with the temperature increasing or decreasing at the rate of $25^{\circ} \mathrm{C}$ per hour in the range from 18 to $95^{\circ} \mathrm{C}$.

With increasing temperature, the two different forms of ammonium myristate, B and A, show different DSC curves, as shown in parts $a$ and $b$ of Figure 7 . The curve for the $B$ form remains the same for three successive run cycles and is very similar to the DSC curve of ammonium stearate, which also crystallizes as the B form (Figure 7c). However, the curve of the A form of the myristate lacks the small peak at $82{ }^{\circ} \mathrm{C}$ seen for the $\mathrm{B}$ form of the myristate and the stearate. The B-form ammonium stearate and ammonium myristate also have pretransition peaks at 78 and $68{ }^{\circ} \mathrm{C}$, respectively, whereas the pretransition peak of the A-form myristate changes drastically depending on the previous history of the sample (Figure 7b). We should note that the corresponding potassium soaps show many DSC peaks and thus many phases at temperatures below that of their main transitions. ${ }^{32}$ 


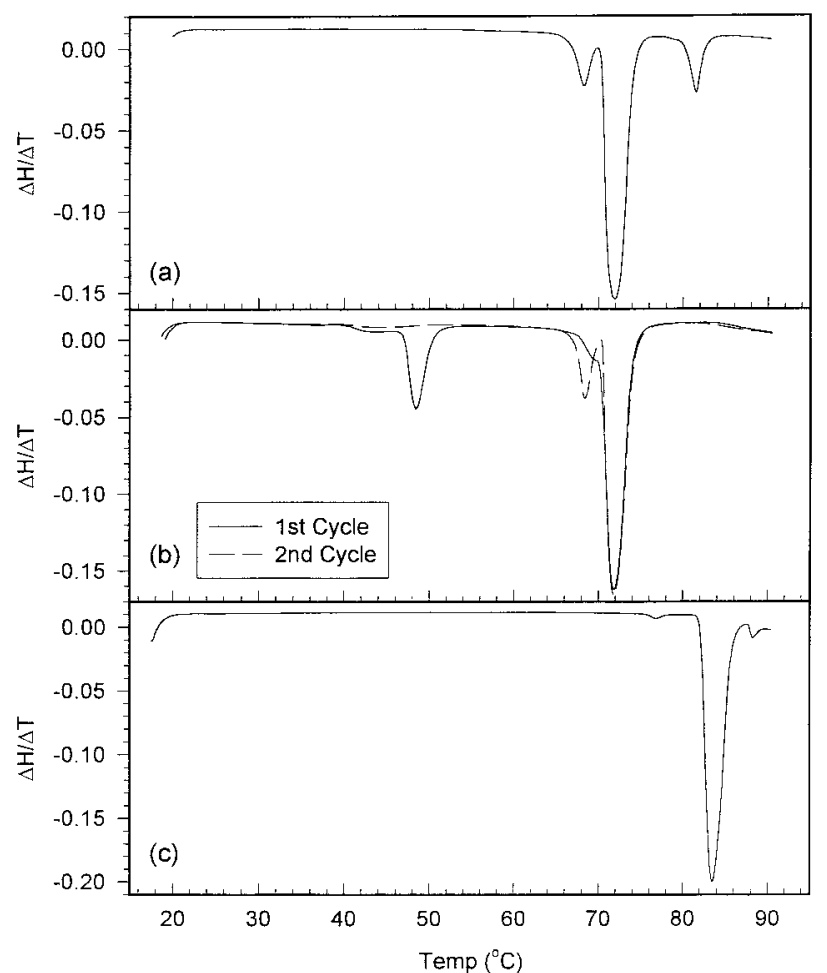

Figure 7. DSC endotherms of the two types of crystalline ammonium myristate and of ammonium stearate. Panel a shows the endotherm for the myristate crystallized from methanol, panel $b$ shows the endotherm for the myristate crystallized from butanol, and panel $\mathrm{c}$ shows the endotherm for the stearate. Note the similarity between panels a and c. As panel $b$ shows, the butanol-crystallized form anneals to the other form on temperature cycling.

Infrared Hole Burning. Our hole burning technique employs ammonium ions containing a small amount of deuterium to form $\mathrm{NH}_{3} \mathrm{D}^{+}$ions, which can have four different orientations in the crystal. ${ }^{15}$ When the laser is set to one of the N-D stretching frequencies, the excitation rotates the ammonium ion. A hole burning spectrum, which is the difference between the absorption spectra before and after the laser irradiation, reveals the population change for each orientation. We normally observe a population decrease (spectral hole) in the band that arises from the irradiated orientation and population increases in the other bands (spectral antiholes).

The hole burning spectra for partially deuterated $(\sim 5 \%)$ ammonium myristate, ammonium palmitate, and ammonium stearate from 2120 to $2300 \mathrm{~cm}^{-1}$ are displayed in Figures 8-10. The bottom panel of each figure shows the absorption spectra with the dark curve for the sample containing the partially deuterated ammonium ion salt $\left(\mathrm{NDH}_{3}{ }^{+}\right)$and the light curve for the nondeuterated one $\left(\mathrm{NH}_{4}{ }^{+}\right)$. The difference between these two (not shown) reveals the features due to the $\mathrm{N}-\mathrm{D}$ stretching vibrations. The results of fitting the $\mathrm{N}-\mathrm{D}$ feature to a sum of Lorentzian bands are summarized in Table 9. As the chain lengthens, the frequency distribution of the $\mathrm{N}-\mathrm{D}$ stretching bands narrows $\left(67 \mathrm{~cm}^{-1}\right.$ for myristate but only 28 and $17 \mathrm{~cm}^{-1}$ for palmitate and stearate) and the width of the component bands decreases. The width (fwhm) for the narrowest component band is $12.1 \mathrm{~cm}^{-1}$ for myristate but 8.6 and $6.2 \mathrm{~cm}^{-1}$ for palmitate and stearate, respectively.

The upper panels of the figures show the hole burning results as the difference between the spectra before and after laser irradiation. The laser burning frequency $\left(\omega_{\mathrm{B}}\right)$ is set near one of the N-D stretching bands and is specified on each displayed spectrum. The hole burning efficiency varies greatly for these

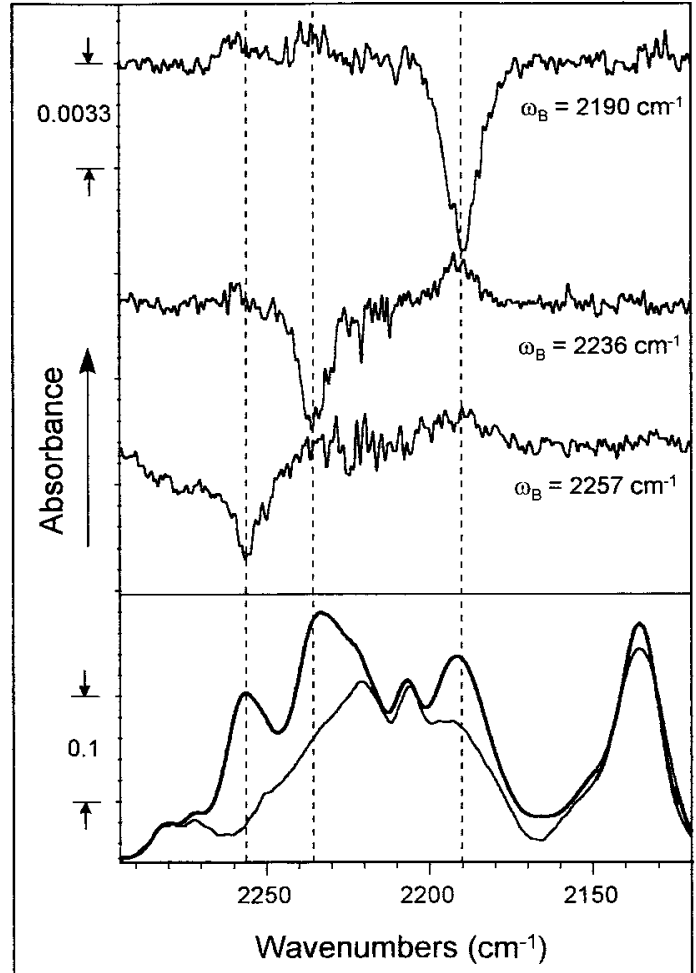

Figure 8. Infrared spectra of ammonium myristate at $7 \mathrm{~K}$ in the $\mathrm{N}-\mathrm{D}$ stretching region. The ammonium ion contains about 5\% deuterium. The absorption spectrum is shown by the heavy line in the bottom panel. The spectrum of the compound without deuterium is shown by the thin line. The top panels are hole burning spectra, displayed as the difference between the spectra before and after irradiation at the individual wavenumbers. The dashed vertical lines are at 2190, 2234, and $2257 \mathrm{~cm}^{-1}$. The holes are provided by a half-hour irradiation. Note the differences in scale between the top and bottom panels.

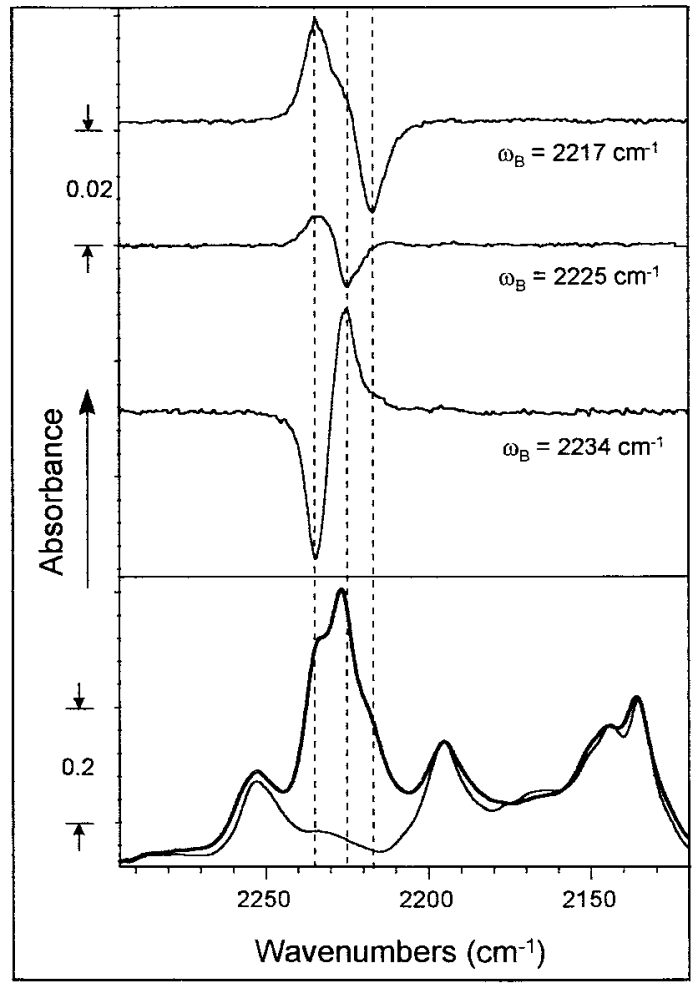

Figure 9. The same as Figure 8 but for ammonium palmitate and for 5 min irradiation. The dashed vertical lines are at 2217, 2226, and 2234 $\mathrm{cm}^{-1}$. 
TABLE 9: Parameters of the N-D Stretching Bands for Ammonium Fatty Salts

\begin{tabular}{|c|c|c|c|c|c|c|c|c|c|}
\hline \multirow[b]{2}{*}{$\mathrm{NH}_{3} \mathrm{D}^{+}$} & \multicolumn{3}{|c|}{ myristate } & \multicolumn{3}{|c|}{ palmitate } & \multicolumn{3}{|c|}{ stearate } \\
\hline & $\begin{array}{l}\text { frequency } \\
\left(\mathrm{cm}^{-1}\right)\end{array}$ & $\begin{array}{l}\mathrm{fwhm}^{a} \\
\left(\mathrm{~cm}^{-1}\right)\end{array}$ & $\%$ area & $\begin{array}{l}\text { frequency } \\
\left(\mathrm{cm}^{-1}\right)\end{array}$ & $\begin{array}{l}\mathrm{fwhm}^{a} \\
\left(\mathrm{~cm}^{-1}\right)\end{array}$ & $\%$ area & $\begin{array}{l}\text { frequency } \\
\left(\mathrm{cm}^{-1}\right)\end{array}$ & $\begin{array}{l}\mathrm{fwhm}^{a} \\
\left(\mathrm{~cm}^{-1}\right)\end{array}$ & $\%$ area \\
\hline 1 & 2257.0 & 10.0 & 29.7 & 2234.6 & 8.7 & 24.4 & 2233.3 & 7.1 & 24.8 \\
\hline 2 & 2233.7 & 14.5 & 40.0 & 2226.5 & 10.4 & 45.5 & 2226.5 & 7.2 & 43.0 \\
\hline 3 & 2190.3 & 15.5 & 30.3 & 2217.1 & 13.3 & 24.3 & 2219.1 & 7.6 & 20.0 \\
\hline 4 & & & & 2206.5 & 17.0 & 5.8 & 2217.2 & 8.9 & 12.2 \\
\hline
\end{tabular}

${ }^{a}$ fwhm: full width at the half-maximum.

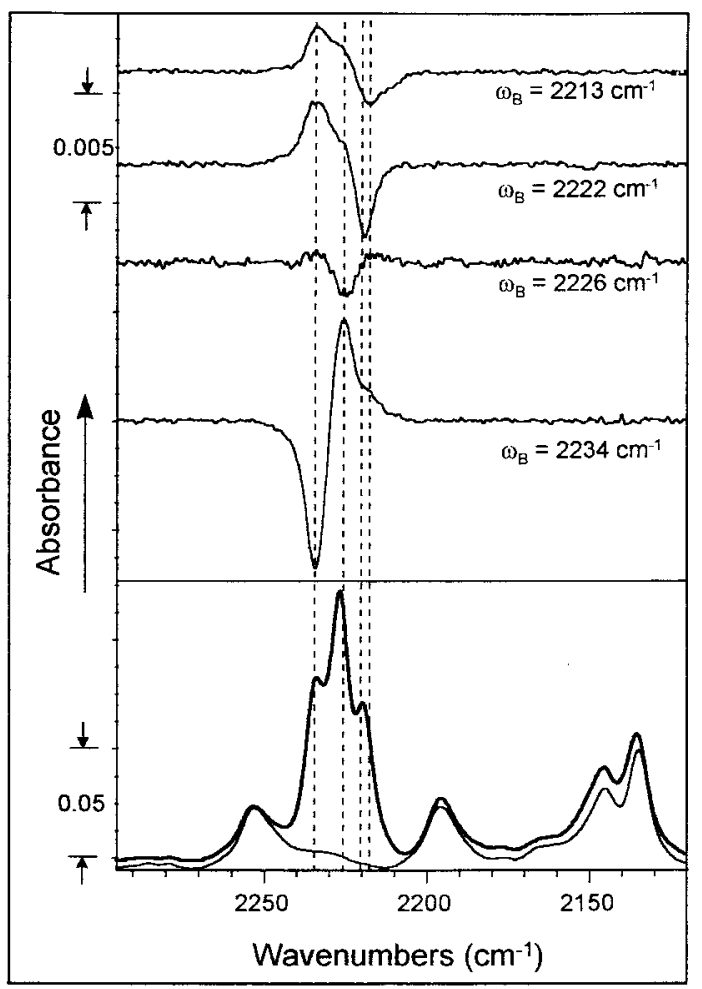

Figure 10. The same as Figure 8, but for ammonium stearate and for 2 min irradiation. The dashed vertical lines are at 2217, 2219, 2226, and $2234 \mathrm{~cm}^{-1}$. Note that the first two lines are not in the same positions as the frequencies of laser irradiation but are at the extrema of the holes/antiholes and of the constituent bands (Table 9).

three fatty acid salts. For ammonium myristate, we irradiate for a half-hour to produce observable hole burning patterns, while 2 min irradiation with the same laser power is sufficient for ammonium stearate and ammonium palmitate.

The hole burning patterns differ in detail among the three compounds. For the myristate (Figure 8), we find only three frequencies that produce observable hole burning patterns rather than four; indeed, we could not find the expected fourth band in the absorption spectrum either (Table 9). The hole burning spectra have very small holes and antiholes, and so the spectra are noisy compared to the spectra of the other two salts. Only one small antihole at $2190 \mathrm{~cm}^{-1}$ appears in the spectra, but it is possible that other antiholes would be evident if the spectra were less noisy. For ammonium palmitate, again only three of the $\mathrm{N}-\mathrm{D}$ bands produce observable hole burning patterns instead of the four component bands identified by fitting. The fourth band may be difficult to burn because of its low intensity. In addition, because the $\mathrm{N}-\mathrm{D}$ frequencies are close to each other in the palmitate, it is hard to see the separate antiholes. However, we do see an antihole at each of the three positions with the smallest antihole at about $2226 \mathrm{~cm}^{-1}$ (in the spectrum with the laser irradiation at $2217 \mathrm{~cm}^{-1}$ ). There are four burnable bands in ammonium stearate, but the antihole patterns are even more difficult to observe because of the closer distribution of four N-D frequencies. Significantly, the holes and antiholes are at the positions of the individual bands found by fitting the absorption spectra. As we have noted before, ${ }^{16}$ the holes are in these positions even if the laser frequency is offset.

The hole burning process prepares the ammonium ion in a nonequilibrium distribution, which then relaxes slowly back to equilibrium. The holes are found to decay too slowly at $7 \mathrm{~K}$, and so the relaxation measurements were done at $52 \mathrm{~K}$ for ammonium palmitate. We followed the change of the hole depth of the irradiated bands as functions of time and found the decay to be exponential. The half-life is $21 \mathrm{~min}$ for irradiation at 2217 $\mathrm{cm}^{-1}, 11 \mathrm{~min}$ for $2226 \mathrm{~cm}^{-1}$, and $22 \mathrm{~min}$ for $2234 \mathrm{~cm}^{-1}$.

\section{Summary}

We have studied the series of ammonium salts of the fatty acids with 14 (myristate), 16 (palmitate), and 18 (stearate) carbon atoms. The X-ray patterns of the myristate and the palmitate yield a crystal structure with the methylene groups arranged in a triclinic subcell. The X-ray study of the stearate yields only the parameters of an unit cell consistent with the same subcell structure. However, infrared absorption and hole burning studies show that the myristate is distinct from the other two and has a structure with two molecules per spectroscopic unit cell. The other two salts have one molecule per spectroscopic unit cell. We suggest this doubling comes from small displacements of the carboxyl groups in the myristate. The hole burning studies reveal systematic differences in the $N-D$ stretches of the three salts. The frequency spacing between the four $\mathrm{N}-\mathrm{D}$ stretches is different in each compound, and this implies that the hydrogen bonding to the ammonium groups is different as well. The widths of the $\mathrm{N}-\mathrm{D}$ absorption bands also varies. The hole burning efficiency is different in the three salts, but the relationship between the geometry of the ammonium site and this efficiency remains to be understood. The decay of the holes was investigated for ammonium palmitate, and the holes were stable at $7 \mathrm{~K}$. At $52 \mathrm{~K}$, they decayed with half-lives of about tens of minutes.

When the myristate was crystallized from different solvents, a second crystal form is found, as shown by DSC and infrared absorption. This form probably has the chains arranged in a complex structure analogous to the A-super form of the fatty acids.

This paper illustrates the rich diversity of crystal structures exhibited by long-chain compounds. This diversity is revealed by a combination of X-ray and infrared absorption studies. The hole burning uncovers further details of the vibrational spectrum: the positions of the individual components of the overlapped bands and relaxation times for rotation of the ammonium ions. Understanding the relationships between structure and the spectral signatures remains for the future.

Acknowledgment. The authors thank Prof. Doug Dorset for helpful discussion and Wenhong Yan for obtaining DSC data 
and are pleased to acknowledge the support of the National Science Foundation (CHE 9815945) and the National Institutes of Health (GM27690).

Supporting Information Available: X-ray structure reports of ammonium palmitate and ammonium myristate. This material is available free of charge via the Internet at http://pubs.acs.org.

\section{References and Notes}

(1) Small, D. M. The Physical Chemistry of Lipids; Plenum Press: New York, 1986. 1240 .

(2) Boistelle, R.; Simon, B.; Pepe, G. Acta Crystallogr. 1976, B32,

(3) Kobayashi, M.; Kobayashi, T.; Itoh, Y.; Chatani, Y.; Tadokoro, H. J. Chem. Phys. 1981, 75, 3175 .

(4) Kobayashi, M.; Sakagami, K.; Tadokoro, H. J. Chem. Phys. 1983, 78,6391 .

(5) Kobayashi, M.; Kobayashi, T.; Itoh, Y.; Sato, K. J. Chem. Phys. 1984, 80, 2897.

(6) Malta, V.; Celotti, G.; Zannetti, R. J. Chem. Soc. 1971, 548.

(7) Goto, M.; Asada, E. Bull. Chem. Soc. Jpn. 1978, 51, 70.

(8) Kaneko, F.; Kobayashi, M.; Kitagawa, Y.; Matsuura, Y. Acta Crystallogr. 1990, C46, 1490.

(9) Kaneko, F.; Sakashita, H.; Kobayashi, M.; Kitagawa, Y.; Matsuura, Y.; Suzuki, M. Acta Crystallogr. 1994, C50, 247.

(10) Kaneko, F.; Sakashita, H.; Kobayashi, M.; Kitagawa, Y.; Matsuura, Y.; Suzuki, M. Acta Crystallogr. 1994, C50, 245.
(11) Dorset, D. L. Private communication.

(12) Goto, M.; Asada, E. Bull. Chem. Soc. Jpn. 1978, 51, 2456.

(13) Pascher, I. Curr. Opin. Struct. Biol. 1996, 6, 439

(14) Snyder, R. G. J. Chem. Phys. 1979, 71, 3229

(15) Strauss, H. L. Acc. Chem. Res. 1997, 30, 37.

(16) Yu, G.-S.; Li, H.-W.; Strauss, H. L. J. Phys. Chem. A 1997, 101 , 8009 .

(17) Goodman, C. H. L. Crystal Growth Theory and Techniques; Plenum Press: London, 1974; Vol. 1

(19) Kung, A.; Fei, S.; Strauss, H. L. Appl. Spectrosc. 1996, 50, 790

(20) Vand, V.; Bell, L. P. Acta Crystallogr. 1951, 4, 465.

(21) Abrahamsson, S.; Dahlen, B.; Lofgen, H.; Pascher, I. Prog. Chem. Fats Other Lipids 1978, 16, 125.

(22) Dumbleton, J. H.; Lomer, T. R. Acta Crystallogr. 1965, 19, 301

(23) Crystallization and Polymorphism of Fats and Fatty Acids; Garti,

N., Sato, K., Eds.; Marcel Dekker: New York, 1988; p 450.

(24) Snyder, R. G. J. Mol. Struct. 1961, 7, 116.

(25) Tasumi, M.; Shimanouchi, T. J. Chem. Phys. 1965, 43, 1245.

(26) Snyder, R. G. J. Mol. Spectrosc. 1960, 4, 411.

(27) Schachtschneider, J. H.; Snyder, R. G. Spectrochim. Acta 1963, $19,117$.

(28) Snyder, R. G.; Schachtschneider, J. H. Spectrochim. Acta 1963 $19,85$.

(29) Snyder, R. G.; Schachtschneider, J. H. Spectrochim. Acta 1965, 21,169

(30) Lomer, T. R.; Perera, K. Acta Crystallogr. 1974, B30, 2913.

(31) Lomer, T. R.; Perera, K. Acta Crystallogr. 1974, B30, 2912.

(32) Ishioka, T. Bull. Chem. Soc. Jpn. 1991, 64, 2174 